\title{
Embedding reflection throughout the postgraduate translation curriculum: using Communities of Practice to enhance training
}

\author{
Sarah Berthaud ${ }^{\mathrm{a}}$ and Sarah Mason $^{\mathrm{b}}$ \\ anternational Hotel School, Galway Mayo Institute of Technology, Galway, Ireland; \\ ${ }^{b}$ School of Languages and Areas Studies, University of Portsmouth Faculty of \\ Humanities and Social Science, Portsmouth, UK
}

\begin{abstract}
The translation industry, as well as Higher Education Institutions (HEIs) and translator training, have undergone numerous changes in the last two decades (e.g. Steward, Orbán, and Kornelius 2010). These changes might explain why there is often a gap between translator training and professional translation practice (Kelly 2015; Kenny and Ryou 2007).

In this paper, we argue that situated learning through the development of a community of practice (CoP) ensures cohesion in individual, group and larger professional contexts. We further argue that reflection elements integrated within the $\mathrm{CoP}$ provide a way to narrow the gap between translator training and professional translation practice.

Unlike previous studies, in this paper we explore how reflection can be embedded during participation and learning throughout the translation postgraduate curriculum to create a CoP. We detail a case-study of the MA in Translation Studies (MATS) at the University of Portsmouth, UK. On the MATS, reflection - for all participants involved - influences all aspects of the course, thereby developing an adaptable CoP that sets both learners and trainers up with the tools for successful adaptation for their professional life.
\end{abstract}

Keywords: Translation, translator training, metacognitive skills, reflection, community of practice, 


\section{Introduction}

Translation is a constantly evolving profession and translation pedagogy should therefore evolve to ensure that translation trainees are adequately trained (e.g. Kelly 2005; Kiraly 2000; Kiraly, Hansen-Schirra, and Makymski 2013). However, despite all the efforts made to date, research suggests that a gap still remains between translator training and the professional translation market at times (Durban, et al. 2003; Kelly 2015; Kenny and Ryou 2007). Even initiatives such as the European Master's in Translation ${ }^{1}$ which was deliberately designed in 2006 by the European Union Directorate General for Translation (EU-DGT) to improve translator training in order 'to ensure a good match between graduates' competences and employers' requirements ${ }^{2}$, has not led to successfully harmonised training across the European Union (Torres-Simón and Pym 2017).

Given the rapid pace of change in both Higher Education and the translation sector, under pressure from forces such as globalisation and technological change, it is not unreasonable to ask whether Higher Education Institutions (HEIs) are in fact able to keep up with such developments. If they are to remain in the running, HEIs must adopt a learning model that can take into account changes affecting all of the actors involved. In particular this means that HEIs must envisage learners as partaking in lifelong learning (Collini 2012). Lifelong learning is not simply about education; it is about learning across the '...school and post-school distinction to suggest a learning process which spans the whole of one's life' (Field and Leicester 2000, xviii). This vision has already permeated translator training (e.g., Kiraly 2000). However, lifelong learning, because it means situated social participation where trainees and the wider community are involved in the learning process, can lead to tensions in education/training delivery. Tensions can arise between a centralisation of education/training power (i.e., decision making) in HEIs and the need to ensure the engagement of the wider civil society (i.e., participants who should be able to make decisions on learning). Too often, lifelong learning is only equated with economic adaptation growth and thus employability (Field and Leicester 2000, xix). In this paper, we argue that Communities of Practice (CoPs) provide a model that allows lifelong learning to take place by minimising tensions and by going beyond employability. It allows the participation of

\footnotetext{
${ }^{1}$ See https://ec.europa.eu/info/european-masters-translation-emt_en

2 This is a quote from the European Union of Associations of Translation Companies, retrieved from https://www.euatc.org/news/item/162-european-masters-in-translation-emt-project
} 
learners and the wider community, the creation of their identities, as well as the engagement and accountability of HEIs within a democratic scene.

We begin by revisiting the definition of a CoP to assess how such communities can provide a learning environment appropriate for changes for all actors implied in the professional translation market, be they language service providers (LSPs), professional associations, translators (trainees and professionals), or trainers. We then explore how CoPs are used in conjunction with reflective practice on the MA in Translation Studies (MATS) at the University of Portsmouth, in order to demonstrate the practicability of using the CoP approach to postgraduate translator training.

\section{Communities of Practice and situated learning}

The concept of the Community of Practice $(\mathrm{CoP})$ is now well established (Lave \& Wenger 1991; Wenger 1998, 2007) and is defined as a group ‘... of people who share a concern or a passion for something they do and learn how to do it better as they interact regularly' (Wenger 2007). Any CoP is essentially bound by these three elements:

- a domain of knowledge that creates a common ground and sense of common identity;

- a community of people who care about the domain and create the social fabric of learning; and

- a shared practice that the community develops to be effective in its domain (CaterSteel et al. 2017, 3).

The above descriptions of CoPs reveal that, within these CoPs, learning is viewed differently from many of the more traditional conceptions: learning is conceived here as a form of situated social participation, not simply as a passive and isolated process. The learner is part of a connected network in which social learning takes place (Kiraly, Hansen Schirra, and Maksymski, 2013). Researchers (e.g. Fuller, 2007; Hughes, Hewson, and Unwin 2007) have identified several advantages to learning within CoPs. The first of these is that learning happens through social interactions and relationships where it is no longer viewed as a purely individual product acquired in isolation from other individuals, rather it occurs within a collective group. In addition, learning in CoPs is not solely offered in the form of content led by teachers from educational institutions or entities: instead, learning can take place outside the classroom, at home or even while following hobbies. In other words: contextualised 
learning occurs in the lived-in world which includes a variety of learning contexts, both informal and formal. Another essential advantage of CoPs is that learning is not solely restricted to the form of knowledge transmitted from experts to novices. Any member of the $\mathrm{CoP}$ might impart knowledge; all of the participants are viewed as active beings. There is no implicit connotation of a passive recipient of knowledge.

Given that learning is conceptualised as a group activity within CoPs, it would be easy to think that CoPs may not be able to provide individuals with the learning outcomes they require. However, Lave and Wenger (1991) have conceptualised a CoP as a situated learning opportunity within which participants are able to create their own identity through participation within the CoP. For instance, participants can view themselves as future professionals of the CoP. This may mean that the participants will not just behave like 'learners' with their colleagues but also like future 'peers'. While creating their individual identity within the CoP, participants can learn what they need, with the learning of each individual shaped by the identity they create. Learning is contextualised and situated. This exceptional structure means that CoPs can provide the required learning outcomes for a multitude of learners with different needs and different identities within a social group. As Eckert (2006, 683) explains, a CoP 'provides an accountable link, therefore, between the individual, the group and place in the broader social order'.

\section{CoPs and translator training}

\section{Identity changes and adaptation}

The adaptability of CoPs to the needs of each individual is extremely relevant in the case of translator training. It is fair to say that over the last two decades, the identities of all actors involved in translator training have changed tremendously due to sector influences such as globalisation, greater competition, lower funding, and technological advancements (see e.g. Stewart, Orbán, and Kornelius 2010). Language Service Providers (LSPs) have had to adapt the services they provide due to technological advancements and the financial repercussions of the 2008 financial crisis (e.g. Sakamoto et al. manuscript). HEIs are not simply institutions providing teaching and learning, they are also centres for research, innovation, enterprise and technology, and even charities ${ }^{3}$. HEIs have evolved extensively in response to employability

\footnotetext{
${ }^{3}$ See http://www.hefce.ac.uk/reg/charityreg/charinfo/\#letterP
} 
demands and technological market changes. Translation Studies is not exempt from such a multi-faceted evolution (see Ródriguez de Céspedes, Sakamoto, and Berthaud 2017). HEIs are now tasked with providing teaching and learning for learners so as to facilitate their access to employment, support their future professional adaptation to job markets and provide them with CPD opportunities. This results in HEIs now operating with multiple - and sometimes conflicting - identities; charity, businesses, trainer, repository of scholarship, to name but a four. Similarly, the teaching staff are operating in multiple identities: they teach but they also conduct research, raise internal and external funds, record impact, publish and disseminate research findings, complete CPD, answer emails, undertake pastoral care, engage with peer and programme evaluation, establish links with partners in the community (e.g., business, academic, or aid sector links), amongst other duties. Such a myriad of identities means that there are several words to describe teaching staff in HEIs. They can be called lecturers, trainers, tutors, and/or teachers. It is beyond the scope of this paper to debate on such labels. However, the multiplicity of identities is worth noting. This shows the complexity of identifying the role of actors within HEIs. For the present paper, we will use the word 'trainer' to describe any person working within a HEI and conducting teaching activities.

However, lifelong learning is not just about employability. It is also about learners developing identities and the participation of wider society (Field and Leicester 2000, xix$\mathrm{xx})$. Like staff in HEIs, similar patterns of multiple identity can be seen among learners, especially in the case of our postgraduate translation cohorts. The learners enrolled on the MATS at the University of Portsmouth are not only enrolled on the MATS to gain employment after completing the course. Our learners currently include graduates fresh from undergraduate courses, but also mature students who wish to change career (and thus adapt to market demands), translators already working in the professional sphere who wish to acquire a postgraduate qualification (thus completing CPD and advancing their professional portfolio), and even translation trainers (see Table 1 and Figure 1 for further details on our cohorts). This list is not exhaustive as motivations can be even more complex than that. In addition to the changes linked to learners' motivations for enrolling on a postgraduate degree in translator training, technological changes have also modified the form and contents of translator training (e.g. Galán-Mañas, and Albir 2010; Varela 2007). Translator training and learning can now take place on campus, online or through blended approaches. These new modes of delivery mean that the learners enrolled on the MATS come from all continents and thus have distinct cultural backgrounds and identities (see Table 1). With employability 
playing such an important role in curriculum design (e.g. Ródriguez de Céspedes, Sakamoto, and Berthaud, 2017), translator training has become an extremely complex beast and clearly, translator training in HEIs is no longer simply a case of individual learning in an educational setting with knowledge transmitted from expert to novice.

\section{[Insert Table 1 near here]}

\section{[Insert Figure 1 near here]}

One way to reconcile all the different identities endorsed by all the actors involved in translator training is via the use of CoPs, as argued by Lea (2005). With all these changes, the translator training offered by HEIs needs to be coordinated within the broader CoP of the translation sector, and must involve the various types of actors within that CoP. Just such a view is reflected in the recent EC-DGT report (as quoted in Massey, and Ehrensberger-Dow $2013,171)$ that calls for: 'the closer integration of universities, industry, and associations'. Such coordinated translator training can equip the learners with adequate awareness of not only potentially beneficial developments that may affect the sector, particularly those relating to changes in the impact from artificial intelligence and machine translation, but also of harmful developments (Esteves-Ferreira et al, 2016). In light of all the recent changes in the translation industry and HEIs, integration with a range of CoPs appears to be the most logical next step in developing a successful theoretical framework for translation pedagogy.

\section{Situated learning and translation pedagogy}

Although CoPs were first developed to account for learning within apprenticeships (Lave \& Wenger, 1991), the theoretical model they offer is also appropriate to improving learning in HEIs. This is particularly the case when applied to postgraduate translator training, as much of the approach used is coherent with the apprenticeship model of vocational training, aiming to prepare graduates for work on the professional market. It thus makes sense to use situated learning methods and methodologies in postgraduate learning and teaching for translation.

However, the use of situated learning methods and methodologies has pedagogical implications. Some research already details how CoPs and situated learning have been and can be applied to translator training to some extent (Calvo 2015; Kiraly 2000; Risku 2016; Stewart, Orbán, and Kornelius 2010). Kiraly (2000) proposes that authentic translation projects allow trainees to learn to work as translators in realistic conditions and prepare them to work as professionals. It develops their self-concept - or psychological identity - and 
allows their socialisation as translators. Calvo (2015), on the other hand, warns trainers about using authentic translation projects for trainees at the beginning of their training process. She argues that such projects may not provide adequate scaffolding, i.e. the project may be too unexpected and therefore difficult for the learners at an early stage of their training. Stewart, Orbán and Kornelius (2010) review the use of cooperative translation to teach medical translation. Their findings show that such collaborative work increases the number of skills acquired by learners and helps them build their identity as future translators. Risku (2016) explains how the use of situated learning for translation research training may benefit learners but warns that using such a pedagogic tool remains difficult for research theory learning.

These papers each tend to focus on just one aspect of translator training: authentic practice projects, medical translator training, and research theory training respectively. We believe, like Kiraly (2013) and D'Hayer (2012, 2013), that CoPs can provide a holistic learning environment for the training of postgraduate translation trainees, allowing them to gain the skills identified as necessary for work as professional translators by the EC-DGT : 'awareness of real-life time, productivity, and efficiency constraints as well as greater learner ability to reflect on their work, monitor their performances, and learn from feedback when it is available' (as quoted in Massey, and Ehrensberger-Dow 2013, 171). The skills identified in this report place an important focus on metacognitive content including: 'talking about one's thinking, writing a thinking journal, self-evaluation and other strategies to solve problems that occur in the learning process' (Choi 2006, 277). These metacognitive skills can be developed through reflective practice and this is an approach that has been used successfully in professional education on a broader front (Lawrence-Wilkes \& Ashmore, 2014). This can be seen among member entities of the Professional Associations Research Network- a body established in 1998 to help shape strong professional entities for the future (Professional Associations Research Network (PARN) 2017). Research has shown that metacognition - or the development of skilled reflection techniques - is crucial for professional translators, enabling them to 'plan, control, and evaluate their problem-solving' (Massey, and Ehrensberger-Dow 2013, 170). This would also equip trainees with the tools to justify and describe their decisions. Massey, and Ehrensberger-Dow further explain that the difference between translation experts and novices is largely that the latter have not developed such skills. Thus, if a programme aims to develop translation experts able to work as professionals, this programme must embed a reflective approach throughout the course content. 


\section{Reflection within CoPs: professional setting for translators and trainers Reflection in the translator training CoP}

Research advocates the use of reflection to enhance learning and professional development (e.g. Lawrence-Wilkes, and Ashmore 2014; Moon 1999). This is of course applicable to translator training. The focus on using reflection to enhance learning in translator training is not new (e.g. Kiraly 2000; Massey, and Ehrensberger-Dow 2013; Orlando 2012). For Kiraly (2000), reflective action should be associated with authentic tasks. Kiraly sees reflection not only as an individual learning aspect but also as a social tool. It facilitates collaboration and communication. It also prepares trainees for the professional world as professional CoPs are characterised by their collective reflective action. Although Kiraly describes how reflection is essential for situated learning, he does not explicitly explain how reflection should be included in curricula and assessed. Echoing Kiraly, Orlando (2012) indicates that both metacognition and self-assessment are crucial factors that influence translation trainees to reflect on their progress and to build their identity as situated learning participants. He puts forward the idea that learners can use a translator's diary to improve the learning of metacognition skills. Massey and Ehrensberger-Dow (2013) likewise explain that reflective practice helps translation trainees develop translation competence. They propose, like Orlando that translation trainees can use learning journals to develop their reflective practice. While these papers provide a solid theoretical framework for the use of reflection in situated learning and CoPs, they do not provide any detailed accounts of how this can be done in practicality, applied throughout the curriculum, or examined.

The minority of the applicants for the MATS come straight from an undergraduate degree, with many taking between one and 20 years before returning to study, meaning that our course provides for the type of learners described by Evans $(2003,57)$ as 'an important category in the universities' contribution to lifelong learning'. The University of Portsmouth deliberately targets individuals seeking a change of career for postgraduate courses as part of their education strategy (University of Portsmouth 2016). All learners on the MATS whether they are young graduates or career changers - must gain knowledge to ensure their smooth insertion into the wider translation CoP. This will give them the greatest likelihood of professional success and identity development. Hence, learners engage with reflective practice to equip them for the challenges to come. In order to do so, the University of Portsmouth is a member of professional associations to ensure that the training provided follows best practice and is integrated into the translation CoP. Because the training offered 
at University of Portsmouth focusses on translation for commercial ends rather than literary translation, the university is an active corporate member of the Institute of Translation and Interpreting (ITI) - the leading UK professional association for translators and interpreters rather than entities such as the Society of Authors Translators Association. The university are also in constant contact with entities and groups such as the Chartered Institute of Linguists (CIoL), the Association of Translation Companies and the All Party Parliamentary Group on Modern Foreign Languages.

\section{Reflection in the broader translation professional CoP: the UK example (ITI and CIoL)}

When learners leave higher education, they will need to continue with deeper engagement in a world of professional interaction with a number of agents to establish and further their careers. These agents will include direct clients, translation corporate entities, informal translator groups and more formal professional entities such as the ITI or the CIoL in the UK (McDonagh 2007).

Leading professional entities in the translation and interpreting sector in the UK are no strangers to the notion that Continued Professional Development (CPD) is an essential feature for a successful career in the current labour market (ITI 2017; CIoL 2017). Both entities are currently working closely with the PARN and they are all too aware that their professional members will need to be adaptable in order to deal with the accelerated rate of change over the coming years as the impacts of globalisation, demands for accountability and technological advances are increasingly felt (Friedman 2013; Lindsay 2014). ITI based the design of the CPD system upon requirements for professionals in related professions in the language services sector, such as teaching, where solid models and good practice were already established on a basis of 'rigorous and critical self-evaluation, reflection and enquiry' (General Teaching Council for Scotland (GTCS) 2012), i.e. on the development of metacognitive skills.

The metacognitive skills for lifelong learning as applicable to ITI and CIoL members can essentially be broken down into the three stages of:

(i) learners setting themselves learning goals;

(ii) learners understanding how they learn best as an individual and;

(iii) learners evaluating their own learning. 
To set goals, learners must understand what a goal is, and they must find those appropriate to their current position and distinguish between long and short-term goals. They need to outline the activities that will help them achieve their goals, identifying obstacles to these and also the resources and sources of support for meeting them. They may need to develop new strategies to achieve the goals, they may need to explore additional educational opportunities (further formal or informal training and qualifications) and work on creating a career plan as part of their coursework.

In the professional sphere, this broad approach can include both formal and informal learning, working on a basis of adaptability (Friedman 2013; Lindsay 2014), and the CPD systems of both ITI (2017) and CIoL (2017c) allow for the logging of any training that leads to an improved professional practice, e.g. use of new tools relevant for the translation industry, marketing training. Good CPD planning - and thus reflection - often responds to a need or desire to shape a career or business. Successful development depends upon the professional learner having identified pertinent weaknesses and areas in need of professional development, self-assessing their current situation and being aware of their preferred learning methods in order to achieve success. The recognised annual cycle of CPD logging, reflection and planning helps lead members of professional associations through the evaluation of their learning, allowing them to monitor and assess progress, identify achieved goals and demonstrate an understanding of what they have learned before moving on to report any new needs or goals, seek new or additional learning opportunities.

Allowing learners to develop metacognitive skills means greater chances of success in a changing world (Coutinho 2007). If they aim to take a serious professional route with their career, they are likely to join a professional association in the longer term, and the code of ethics of many such groups around the world will include a section on CPD. For instance, the ITI 'professional competence' section of the code of professional conduct states that all members, including corporate members and their translator and interpreter employees, are 'required to undertake continuing professional development as appropriate, in order to continue to offer the highest possible standards of work my maintaining and updating their language skills, subject knowledge or any other skills or knowledge necessary for the work'(ITI 2017b).

The models used for the reflective process are similar to the adult continuing and professional learning model developed in Merizow's (2000) transformative learning the measurable outcomes of which can essentially be summarised as: (i) critical reflection on assumptions; (ii) discourse to validate insights from critical reflection; (iii) action. Merizow's 
model also imply active involvement from the learner comprising spiritual, emotional and psychological aspects beneficial to their on-going future development. To address such considerations, the long-term design for the process of logging CPD within the ITI system includes a reflective section where the professional provides the reasoning for their choice of training activity and their opinion of both what they learned and what gaps remain in their knowledge or practice. Both ITI and CIoL (2017) include an additional slot for evaluation after the action phase, in order to help shape the future CPD plan reflectively.

Given that the broader professional CoP takes metacognitive skills into consideration for the professionals' development, trainers in translation studies, like trainers for other disciplines, must ensure that learners gain such skills, not only on a one-off basis purely for the education purpose but on a holistic basis for participation in lifelong learning, one valuable outcome of which should be enhanced employability. In this paper, we want to show through a detailed practical case study that, within the CoP theoretical framework, it is possible to embed reflection throughout the curriculum so that every aspect of postgraduate training provides an opportunity to develop metacognitive skills - as an individual and as a participant in the $\mathrm{CoP}$ - and thus develop identity and participation for all actors of the training. We further argue that CoPs, and a thorough embedding of reflection in the curriculum, present an opportunity to provide adaptable learning to postgraduate translation trainees for lifelong learning.

\section{Reflection within the MATS: case study of units offered within the MATS at the University of Portsmouth}

\section{Reflection within Critical Approaches to Specialised Translation (CAST)}

The CAST unit is a compulsory year-long unit for the learners of the MATS. It aims to simultaneously foster learning of translation theory and develop critical reflection and metacognitive skills to improve specialised translation practice in line with the skills required to work as a professional translator (Massey, and Ehrensberger-Dow 2013). Critical reflection and metacognitive skills allow learners to consider a problem and the various options available, then take a decision depending on such considerations. Thus, it becomes logical to link translation theory learning to reflection and metacognition in order to solve 
translation problems. Thus, as part of CAST, the learners study both a language specific component and a non-language specific component where theory and reflection are linked.

In the non-language specific component, the learners are introduced to translation theory and its implications for translation in the form of a weekly workshop. The learners enrolled in the campus-based option attend the seminar on campus. The learners who are enrolled in the distance learning course complete this component online. For each workshop, the learners are asked to reflect on some practical issues prior to the workshop (e.g., readings on gender issues in translation, reflecting on cross-linguistic differences, gender and politics in translation, reflection on their approach to translating gender). During each workshop (whether campus-based or online), the learners discuss their findings and reflections among themselves with guidance from the trainer. Their reflections constitute a solid basis upon which to build their theoretical knowledge, metacognitive skills and identity. They can apply the learning and reflections garnered here in the more practical applications offered in the language specific component of the unit.

The language specific component is usually delivered in distance learning mode due to student numbers and the fact that the bulk of the MATS cohort is enrolled on the distance learning option. In the language specific component, the learners work online in small groups (normally of three or four people). Over the two teaching blocks, the learners work within four specialised translation fields, chosen according to the expertise of the translation trainers (including commercially viable areas, e.g., medical, legal, journalistic, and technical translation). All of the trainers have experience as professional translators and thus can ensure that the tasks emulate to real-life jobs. Realistic projects ensure scaffolding during learning while maintaining the highest possible level of authenticity (Calvo 2015). Real projects can be too difficult or impossible to find in sufficient quantity for the cohort.

For each CAST training task, the learners respond to a translation brief (i.e. to complete a translation to fictive requirements that match real-life requirements) and provide a group commentary or reflective statement on aspects of the translation. These two elements group commentary or reflective statement - include glossary compilation, commentary writing, corpora use, theoretical research. For each field of specialised translation, the learners complete tasks working into both their first language (L1) and second language (L2), before finally completing Task 3 usually into their own L1. Tasks 1 and 2 are used as formative assessment tools and initiate the learners to working in groups online; Task 3 is used as both a formative and summative assessment tool and is completed on an individual basis. For Tasks $1 \& 2$, the learners collaborate and decide who is going to complete which 
part of the task, they must liaise with each other and the receiver of the task, and troubleshoot any arising issue (e.g., issues of group dynamics, sharing of resources, consultation of experts). The tasks within the blocks of the unit build in complexity in a way that provides scaffolding (Calvo 2015) and also cooperation (Stewart, Orbán, and Kornelius 2010). The structure also ties in neatly with the EC-DGT requirements for deadlines, reflection, monitoring and learning from feedback, as, for the most part, collective feedback is given during class sessions or on discussion boards allowing members of our learners' CoP to learn from both the trainer and their peers.

In addition to completing the translation-related tasks, the learners are invited to compile a commentary, based on the notes they each have kept, in order to link their practice to the theory reviewed in the non-language specific component. For Task 3, the learners complete a defined translation task to a full brief, this time working into their L1 (except for the commentary). This is undertaken and submitted individually but the structure of the work flow through each 6-week block allows them to draw on their previous group reflective practice in the commentary-writing section of the task. The different tasks involved have been chosen to ensure that all assessments - summative and formative - include reflective practice to develop the metacognitive skills of the learners. The feedback they receive for each task can therefore be used to improve on the following tasks.

\section{Reflection within Professional Aspects of Translation}

The Professional Aspects of Translation unit was deliberately designed to build on the strengths of our department and the solid background of our staff members in professional practice (e.g. non-governmental organisations and international aid, journalism, legal, medical). In producing the unit, members of staff have drawn upon their own experiences and reflective practices initially as early career translators and later as team members or leaders, to provide learners with opportunities to expand their understanding of the key building blocks of an early career. The sessions aim to primarily prepare learners to enter the translation market as free-lance translators: preparing for work as a translator or setting yourself up in business as a freelance translator.

To ensure that the learners benefit from these sessions, they are asked to engage their metacognitive skills from the beginning by posting an analysis giving their current reflection on their position within the translation profession, stating what they perceive to be their immediate strengths and weaknesses, alongside what they class as the opportunities threats 
facing them (i.e., a SWOT analysis). They are expected to enter a minimum of five items for each class of content.

They post their rough first draft onto the group discussion forum for informal feedback from their peers, priming the pump for reflection upon their own situation within a realistic framework. This SWOT analysis will form the basis for the development of their business and CPD plan as they reflect upon how to approach the issues they have listed in order to move them from the negative side of the equation to the positive.

Our main aim in this unit, then, is to provide the learners with connections with the real world of translation, linking them up with each other, introducing them to basic business models they may encounter and connecting them to both informal and formal translator and client networks. The plan is for them to leave with a personal operational skeleton CoP already in place. The learners are also given a full model for setting up a freelance business based on real experience in the UK that they are encouraged to adapt to their own needs and possibilities. The greater underlying aim is learners to be equipped with a personal internalised process they can apply to future planning of their learning and business strategies as they adapt to opportunities in the ever-changing working world of their futures on a basis of solid self-knowledge and sound links to their CoP.

Throughout the teaching the learners have access via our learning platform to input from a wide range of practitioners through presentations recorded at seminars and conferences. Contributors are selected by staff from their own professional networks on the criteria of being successful practitioners, expert communicators and original thinkers. This ensures that the learners are being exposed to premium content from high-quality speakers, providing a good, solid basis for reflection on content acceptable to even the most demanding translator CoP.

Learners also have access to a wide range of support from the Department of Employability, and the University's Student and Graduate Enterprise Team lead the learning activities related to self-marketing, business start-up, job application and job search.

The unit is, by necessity, a flexible professional planning model adaptable to our wide range of learners (see Table 1 and Figure 1). Over the course of the unit the learners form links with translation associations and groups in their own language pairs and geographical areas, they explore current workflows and organisational models in the language services sector and research deeply and broadly in their own environment. They are thus engaging with their own CoP. The importance of this cannot be overstated as the translation market situation varies immensely depending on the status of the profession in each geographical 
area and even between the language pairs within these (Dam 2016; Pym 1998; Pym et al. 2016; Orrego Carmona, and Torres Simon 2016). By supporting our learners to prepare as fully as possible for their individual situation, we can ensure their reflection is as welltargeted, realistic and applicable as possible.

At the end of taught content of the unit, our learners are encouraged to revisit their initial SWOT analysis and to reflect upon it in the light of all they have learned. They apply a process similar to that recommended by the ITI (2017) and CIoL (2017) to reconsider and update this, and the refreshed SWOT analysis is generally submitted as part of the final portfolio. We encourage learners to follow a positive reflective approach where a successful piece of work will include strategies and plans to overcome the 'weaknesses' and reduce the 'threats' through strategic entrepreneurial thinking, CPD planning and identity development. The business and CPD plan they produce will then help them to take the fullest possible advantage of their identified strengths and opportunities and to approach or overcome their weaknesses and threats in order to build a successful professional practice that can be integrated into the professional CoP

Requirements for the final assessment include a targeted CV and cover letter for a real job opening the learner has identified, accompanied by a full SWOT analysis, business and CPD plan for 5 years, with a full bibliography and list of references. These submissions are marked on the quality and depth of research, overall structure and coherence, practicality and, most importantly, self-awareness. The final element is generally expressed in the form of a reflective passage by the learner describing their current position and their intended end point and how they aim to get from the one to the other.

The learners are expected to create a full and coherent plan for their own progress, based on their current position, and the best learners will show excellent research that clearly identifies the relevant business and professional CoPs, those that are potentially capable of offering them access to the CPD opportunities they will require to further their careers. Given the global nature of our student cohort, the success of the reflective process in the argument is essentially judged on the learner producing a coherent and well-structured plan on the basis of their own individual position in terms of skills, experience, geography and potential markets that demonstrates high levels of reflection and self-knowledge and that equips them to plug directly in to their local CoPs.

\section{Reflection \& employability: for a broader community of practice}

\section{Research, employability, and a community of practice}


As mentioned previously, as trainers we work with multiple identities on a day-to-day basis. All of our trainers have professional translating experience and are also engaged in research and CPD. This means that all trainers may belong to several CoPs (see Figure 2 for an example), which can overlap to some extent. For instance, as a researcher a translation trainer can conduct research that will be relevant for both the professional translation $\mathrm{CoP}$ and the academic translation studies CoP. Such an overlap can be used to advantage in dialogue and reflection with all parties involved. It allows us to include both the broader $\mathrm{CoP}$ and the narrower CoPs (Hodkinson \& Hodkinson 2004).

\section{[Insert Figure 2 near hear]}

With this in mind, reflection and research are deeply embedded at the University of Portsmouth for the benefit of all participants of the various CoPs. For instance, the translator training team meets on a regular basis to organise research events pertinent to undergraduates, postgraduates, and the wider translation industry (associations, LSPs, professional translators and interpreters). One example of such an activity is the yearly conference organised at the university every November. The conference topic is not only topical but also closely linked to the research areas of each member of the training team. At present, the team is working on examining the impact of new technologies on language service providers. A first symposium on this topic was organised in June 2016, with contributions from UK LSPs (local and national), established researchers and Henry Dotterer, owner of the ProZ translator forum and learners were also invited to attend. The symposium gave the translator training team and the learners an opportunity to assess the impact of new technologies on the industry from the point of view of LSPs. The findings of the research are directly applicable to our teaching and learning: the point of view expressed by LSPs constitutes a solid basis to assess how technological tools can facilitate and hinder the everyday work of LSPs, their translators and their clients. The research team can thus focus on working at disseminating such findings to raise awareness about the issues encountered and thus lead to improvements on the matter. Such improvements will have repercussions for translator training and therefore translation trainees. Trainers play an important role in that they must reflect on their research findings so as to adapt their teaching - both content and approaches - to ensure the sustainability of the training offered. This also means better integration between HEIs, LSPs, translators, and clients. This in turns makes the CoP more integrated and more resilient.

\section{Practice and reflection outside the university}


Our work in teaching translation here within the university is assisted by our links to the professional field, and many of the events we run cross the boundaries from within the university to outside. As part of our 'Engaging with the Profession' activities, the university organises upward of six public talks each academic year, drawing on our personal and professional connections to provide our learners and our local translator CoPs with timely updates on various aspects of the profession. Sessions so far can cover topics such as: linguists in the armed forces, translation environment tools (TEnTs) (and the computer aided translation (CAT) tools, that form part of these), what a professional needs to know, and the technical model used by Translators Without Borders. These talks often inform our learners of opportunities or areas of knowledge they would not otherwise have covered within the core course content, and this contributes to the reflective processes of trainers and learners alike, feeding the breadth of our aspirational thinking on new possibilities for course content or independent follow-up learning activities.

The University of Portsmouth has exceptionally strong links with the broader translation CoP as mentioned previously. We believe these contacts help us to keep abreast of change and to provide appropriate material for discussion and reflective practice both within our immediate $\mathrm{CoP}$ and beyond. Filming these talks and presentations allows us to pass on much of the content for our distance-learning students and boosts the quality of their reflection. The provision of such content allows learners and practitioners alike to reflect upon their current practices and outlooks, to refine and improve these, and thus contribute to a virtual cycle of improved professionalism that benefits all members of these CoPs and strengthens the professional status of the sector.

\section{Conclusion}

The translation industry has undergone tremendous changes in the past two decades. The changes have happened as a result of new technological developments, ensuing modified practices, and globalisation of the translation market and the Higher Education market. Such changes have generated gaps and have forced HEIs to rethink the translator training provided. The examples we have used show that using situated learning - in particular focussing on the acquisition of metacognitive skills - can facilitate the integration of learners into the professional CoP. We have further showed that the acquisition of such skills can be facilitated by holistically embedding reflection in the postgraduate translator training 
curriculum for the benefit of all participants - learners and others - of the professional CoP. Embedding reflection holistically means that the learners, when they leave HEIs, can undertake reflective practice independently and continue developing their own identity. This will give them the adaptability and resilience needed to tackle changes within the $\mathrm{CoP}$ and/or developing their own identity throughout the length of their career, thus enabling lifelong learning and going beyond employability. This can only be achieved if participants of the already established CoP - trainers, HEIs, LSPs, professional translators, clients - are in dialogue to reflect on changes and ensuing needs so as to liaise with learners. We believe that this dialogue within the CoP will strongly contribute to bridging the gaps that exist between training and professional practice.

\section{References}

Calvo, Elisa. 2015. "Scaffolding translation skills through situated training approaches: progressive and reflective methods." The Interpreter and Translator Trainer 9 (3): 306-322.

Cater-Steel, Aileen, Jacquie McDonald, Peter Albion, and Petra Redmond. 2017. "Sustaining the momentum: A cross-institutional community of practice for research supervisors." In Implementing communities of practice in higher education: Dreamers and schemers, by Jacquie McDonald and Aileen Cater-Steel, 3-18. Singapore: Springer Singapore.

Chartered Institute of Linguists (CIoL). 2017. Continuing Professional Development. 10 March. http://www.ciol.org.uk/cpd.

Choi, Jung Yoon. 2006. "Metacognitive evaluation method in consecutive interpretation for novice learners." Meta 51 (2): 273-283.

Collini, Stefan. 2012. What are Universities for? London: Penguin.

Coutinho, Savia A. 2007. "The Relationship between Goals, Metacognition, and Academic Success." Educate 7 (1): 39-47.

Dam, Helle V. 2016. "The translation profession: centres and peripheries. Introduction." JoSTrans (25): 1-13. 
D'Hayer, Danielle. 2013. "Public service interpreter education. A multidimensional approach aiming at building a community of learners and professionals." In Interpreting in a changing landscape, by Krzysztof Kredens, Christina Schäffner and Yvonne Fowler, 321-337. Amsterdam: John Benjamins.

D'Hayer, Danielle. 2012. "Public service interpreting and tranlsation: moving towards a (virtual) community of practice." Meta LVII (1): 235-247.

Durban, Chris, Tim Martin, Brian Mossop, Ros Schwartz, and Courtney Searls-Ridge. 2003. "Translator Training \& the Real World: Concrete Suggestions for Bridging the Gap (Round Table)." translationjounal.net. January. Accessed March 20, 2017. http://translationjournal.net/journal/23roundtablea.htm.

Eckert, Penelope. 2006. “Communities of practice.” In Encyclopedia of language \& linguistics, by Keith Brown, Laurie Bauer, Margie S. Berns, James Edward Miller and Graeme Hirst, 683685. Amsterdam: Elsevier.

Esteves-Ferreira, João, Juliet Macan, Ruslan Mitkov, and Olaf-Michael Stefanov. 2016. "Translating and the Computer 38." Conference Proceedings. London: AsLing.

Evans, Norman. 2003. Making Sense of Lifelong Learning: Respecting the Needs of All. London and New York: Routledge Falmer.

Field, John, and Leicester, Mal, eds. 2000. Lifelong Learning: Education Across the Lifespan. Florence: Taylor and Francis. Accessed July 18, 2017.

Friedman, Andrew L. 2013. Continuing Professional Development: Lifelong Learning of Millions. London: Routledge.

Fuller, Alison. 2007. "Critiquing theories of learning and communities of practice." In Communities of practice: Critical perspectives, by Jason Hughes, Nick Jewson and Lorna Unwin, 17-29. London/New York: Routledge.

Galán-Mañas, Anabel, and Amparo Hurtado Albir. 2010. "Blended learning in translator training." The Interpreter and Translator Trainer 4 (2): 197-231.

General Teaching Council for Scotland (GTCS). 2012. "Standard for Career-Long Professional Learning (draft)." General Teaching Council of Scotland. August. http://www.gtcs.org.uk/web/FILES/about-gtcs/standard-for-career-long-professionallearning-draft-august-2012.pdf.

Hughes, Jason, Nick Hewson, and Lorna Unwin. 2007. "Communities of practice: A contested concept in flux." In Communities of practice: Critical perspectives, by Jason Hughes, Nick Hewson and Lorna Unwin, 1-16. London/New York: Routledge.

Institute of Translation and Interpreting (ITI). 2017. Code of Professional Conduct. 10 March. http://www.iti.org.uk/become-a-member/code-of-professional-conduct.

—. 2017. Professional Development. 10 March. http://www.iti.org.uk/professional-developmentevents/cpd. 
—. 2017. Professional Development Events. 10 March. http://www.iti.org.uk/professionaldevelopment-events/cpd/151-why-do-i-need-cpd.

Kelly, Dorothy. 2005. A Handbook for translator trainers. A Guide to reflective practice. Manchester: Saint Jerome.

Kenny, Dorothy, and Kyongjoo Ryou. 2007. Across Boundaries: International Perspectives on Translation. Newcastle upon Tyne: Cambridge Scholars Publishing.

Kiraly, Don. 2000. A social constructivist appraoch to translator education. Manchester: Saint Jerome.

Kiraly, Don. 2013. "Towards a view of translator competence as emergent phenomenon: Thinking outside the box(es) in translator education." In New prospects and perspectives for educating language mediators, by Don Kiraly, Silvia Hansen-Schirra and Karin Maksymki, 197-224. Tübingen: Narr Verlag.

Kiraly, Don, Silvia Hansen-Schirra, and Karin Maksymski. 2013. New prospects and perspectives for educating language mediators. Tübingen: Narr Verlag.

Lave, Jean, and Etienne Wenger. 1991. Situated learning: Legitimate peripheral participation. Cambridge: Cambridge University Press.

Lawrence-Wilkes, Linda, and Lyn Ashmore. 2014. The reflective practitioner in professional education. Basingstoke: Palgrave Macmillan.

Lea, Mary R. 2005. "Communities of practice in higher education: Useful heuristic or educational model?" In Beyond communities of practice: Language, power, and social context, by David Barton and Karin Tusting, 180-197. Cambridge: Cambridge University Press.

Lindsay, Hilary. 2014. Adaptability, The Secret to Lifelong Learning. London: PARN.

Massey, Gary, and Maureen Ehrensberger-Dow. 2013. "Evaluating translation processes: Opportunities and challenges." In New prospects and perspectives for educating language mediators, by Don Kiraly, Silvia Hansen-Schirra and Karin Maksymki, 157-180. Tübingen: Narr Verlag.

McDonagh, Julie. 2007. "How do Language Professionals Organize Themselves? An Overview of Translation Networks.” META 524: 793-815.

Mezirow, Jack. 2000. Learning as Transformation: Critical Perspectives on a Theory in Progress. San Francisco: Jossey Bass.

Moon, Jennifer A. 2006. Learning Journals: A Handbook for Reflective Practice and Professional Development. London: Routledge.

- 1999. Reflection in learning and professional development: Theory and practice. London/New York: RoutledgeFalmer.

Professional Associations Research Network (PARN). 2017. Parnglobal. 10 March. http://www.parnglobal.com. 
Pym, Anthony. 1998. "On the market as a factor in the training of translators." Anthony Pym. Accessed March 17, 2017. http://usuaris.tinet.cat/apym/on-line/translation/market.html.

Pym, Anthony, David Orrego-Carmona, and Esther Torres-Simon. 2016. "Status and technology in the professionalisation of translators. Market disorder and the return of hierarchy." JoSTrans (25): 54-73.

Risku, Hanna. 2016. "Situated learning in translation research training: academic research as a reflection of practice." The Interpreter and Translator Trainer 10 (1): 12-28.

Ródriguez de Céspedes, Begoña, Akiko Sakamoto, and Sarah Berthaud. 2017. "Employability and the translation curriculum." Interpreter and Translator Trainer.

Sakamoto, Akiko, Begoña: Berthaud, Sarah Rodríguez de Céspedes, and Jonathan Evans. Manuscript. "UK LSPs' perception about and strategies for technological advancement and disruption." Hermes: Journal of Communication and Business.

Stewart, John, Wencke Orbán, and Joachim Kornelius. 2010. "Cooperative translation in the paradigm of problem-based learning." In T21N - Translation in Transition 2010-01, by Viktoija Bilic, Anja Hoderbaum, Anne Kimmes, Joachim Kornelius, John Stewart and Christop Stoll, 10-18. Trier: Wissenschaftlicher Verlag Trier. http://www.t21n.com/homepage/articles/T21N-201001-Stewart,Orban,Kornelius.pdf.

Torres-Simón, Ester, and Anthony Pym. 2017. "European Masters in Translation. A Comparative Study.” February. Accessed February 20, 2017. https://www.academia.edu/31635052/European_Masters_in_Translation._A_comparative_stu dy.

University of Portsmouth. 2016. "Education Strategy 2016-2020." Realising the Vision: Strategy. Accessed January 13, 2017. http://www. University of Portsmouth /realising-thevision/strategy/.

Varela, Maria José. 2007. "How new technologies improve translation pedagogy."

Translationjournal.net. October. Accessed February 20, 2017. http://translationjournal.net/journal/42technology.htm.

Wenger, Etienne. 2007. "Communities of practice. A brief introduction." http://www.ewenger.com/theory/.

—. 1998. Communities of practice: Learning, meaning, and identity. Cambridge: Cambridge University Press. 


\begin{tabular}{|l|l|c|c|c|}
\hline Origin & Age group & $\mathbf{2 0 1 3 - 2 0 1 4}$ & $\mathbf{2 0 1 4 - 2 0 1 5}$ & $\mathbf{2 0 1 5 - 2 0 1 6}$ \\
\hline Home/EU & $\mathbf{2 1 - 2 5}$ & 30 & 35 & 24 \\
\hline & $\mathbf{2 6 - 3 5}$ & 62 & 73 & 90 \\
\hline & $\mathbf{3 6}$ and over & 54 & 64 & 90 \\
\hline International & $\mathbf{2 0}$ and under & & 1 & 2 \\
\hline & $\mathbf{2 1 - 2 5}$ & 1 & 2 & 31 \\
\hline & $\mathbf{2 6 - 3 5}$ & 19 & 23 & 18 \\
\hline & $\mathbf{3 6}$ and over & 16 & 15 & \\
\hline
\end{tabular}

Table 1: Number of learners enrolled on the MATS according to origins (Home/EU; International) and age groups 
Figure 1: Map of learners enrolled on the MATS for academic year 2014-2015

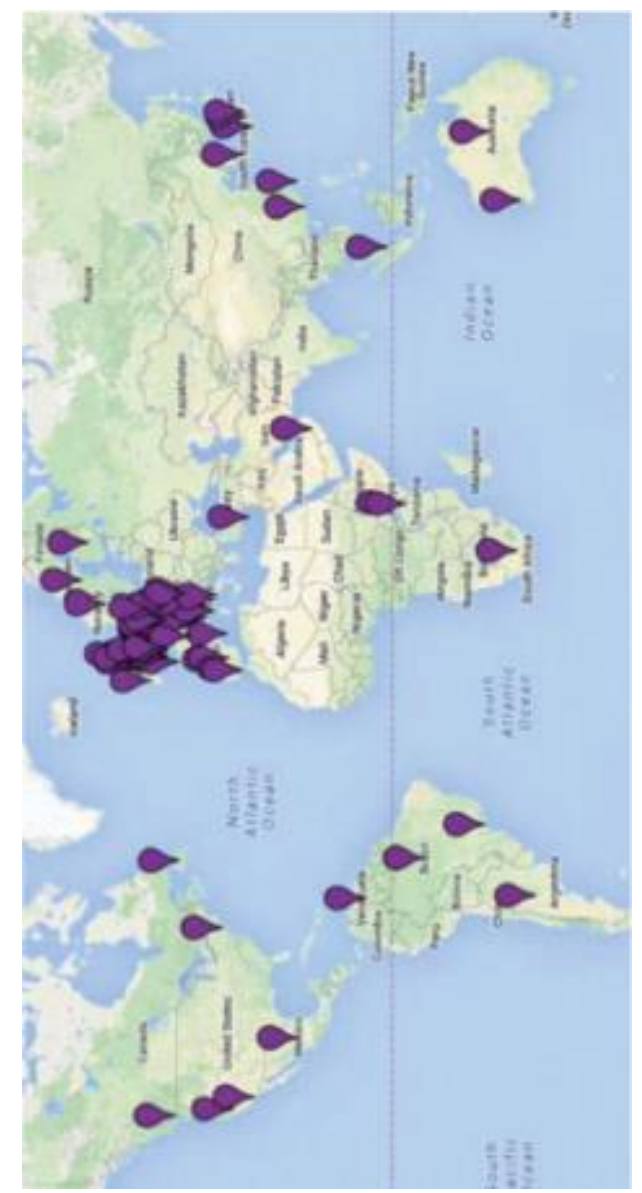

Figure 2: Example of CoPs for translation trainers and trainees

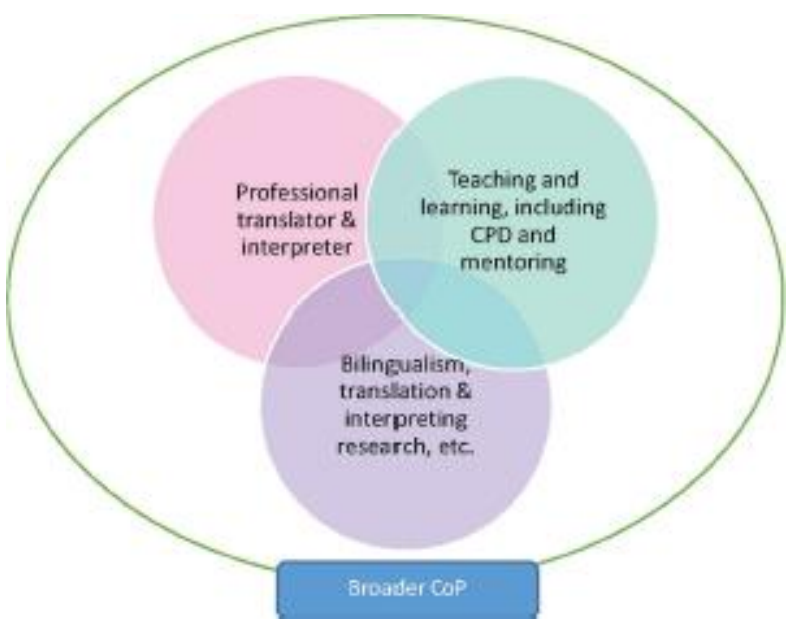

(7854 words in the non-anonymised document) 